\title{
Developing a model of four-year aviation program quality:
}

\section{A grounded theory approach}

\author{
Paul D. Lindseth \\ University of North Dakota
}

\begin{abstract}
There has been a rapid increase in the number of four-year aviation programs in the U.S., from 20 programs in 1968 to over 70 programs today (UAA, 1994). The quality of these programs is difficult to determine since no research, other than accreditation standards, could be found concerning what criteria comprise a high quality four-year aviation program. Furthermore, having aviation professionals prepared through quality academic programs seems essential for the safe operation of the U.S. air transportation industry. The purpose of this qualitative study was to identify criteria that support a definition or theory of quality within fouryear aviation programs in the U.S. Using Glaser and Strauss' (1967) grounded theory approach, data were collected from U.S. baccalaureate aviation program administrators and directors of training from U.S. major, national, and regional airlines. Eighty-two responses (63\% response rate) were used in the analysis. Categories of criteria emerging from the study, such as curriculum, students, and faculty, were used to develop a model for four-year aviation program quality. Results of this study have implications for aviation program administrators and faculty for developing higher quality four-year aviation programs by placing more emphasis on identified criteria of program quality.
\end{abstract}

\section{Introduction}

Professional baccalaureate aviation programs have increased in numbers during recent years throughout the United States. In 1968 there were approximately 20 baccalaureate aviation education programs in the country, according to the University Aviation Association (UAA), the only professional organization representing the non-engineering element in collegiate aviation (UAA, 1989, 1994). Today there are 70 baccalaureate aviation programs in the country offering flight education in conjunction with a four year degree (UAA, 1994). Other related specializations offered by these baccalaureate aviation programs include airport management, aviation administration, aviation maintenance management, and air traffic controller education.

A rapid expansion of America's air transportation industry from 182 million passenger miles flown in 1982 to over 400 million passenger miles flown in 1991 (Wells, 1993) is a main factor for the increased number of aviation programs along with a decreasing number of exmilitary pilots since the 1970s (Federal Aviation Administration [FAA], 1993). The significant increase in passenger miles flown requires a greater number of aviation personnel along with more sophisticated technology and equipment to operate in the same amount of airspace. As a result, aviation professionals must be more knowledgeable, better prepared, and more capable of making critical decisions to continue to ensure the safety of passengers, flight crew members, 
and the general public. Because pilots, aviation and airport managers, administrators, and air traffic controllers are in command of hundreds to thousands of lives daily, these professionals need superior preservice programs. Having aviation professionals prepared through quality academic programs is essential for the safe operation of today's and tomorrow's air transportation industry.

\section{Background Literature}

The literature on academic program quality in higher education can be categorized into areas of emphasis. These areas are: 1) context and input indicators of quality, 2) process and outcome indicators of quality, and 3) literature addressing a shifting view toward academic program quality.

\section{Context and Input Indicators of Program Quality}

In a review and critique of literature and research concerning program quality in higher education, Conrad and Blackburn (1985b) advanced the argument that academic quality "in this country has multiple dimensions and can be seen in many contexts” (p. 285). Most scholars agree that quality is not likely to be the same at different types of academic institutions (Astin, 1985; Conrad \& Wilson, 1985; Millard, 1991). High quality programs in research universities as compared to high quality programs in community colleges will have different attributes. However, after synthesizing the literature, Conrad and Blackburn (1985b, p. 285) give the following elements commonly found in quality academic programs:

1) Faculty: quality programs are almost always related to characteristics of the faculty responsible for the implementation of the curriculum;

2) Facilities: quality programs have facilities necessary for their success such as well-equipped laboratories, appropriate library holdings, computers, and all the material things needed for the desired learning to take place;

3) Finances: quality programs have adequate financial support including the resources to maintain the operation, provide for faculty travel, and attract and retain outstanding faculty;

4) Curriculum: quality programs have a curriculum which has sufficient breadth and depth of courses; and

5) Students: quality programs have a sufficient number of students to provide for an adequate mix to foster students’ learning from one another, and yet not so many students that individualized attention is lost.

Kuh’s (1981) extensive literature review used Stufflebeam’s context-input-processproduct model (Stufflbeam et al., 1971) to identify indices of quality in undergraduate programs. Context indicators of quality were size, clarity and consistency of institutional purpose, organization processes (i.e. decision making strategies), financial resources, and student living environments (Kuh, 1981). Input indicators of quality identified in the model were student ability and student demographics, as well as nonintellectual characteristics such as aspirations 
(Kuh, 1981). 


\section{Process and Outcome Indicators of Program Quality}

Academic programs having context and input indicators of quality may not be deemed of high quality after assessing educational process or outcome variables as indicators of quality. Conrad and Blackburn (1985b) identified other correlates of program quality that are educational process or outcome variables. These correlates are less quantifiable, and include "leadership of program administrators, esprit of students and faculty, morale of students and faculty, clarity of purpose, and a healthy organizational climate” (p. 286). Esprit was described as a cooperative attitude among students as well as among faculty, whereas morale was more of an individual student and faculty trait. Although studies listing these characteristics as quality program indicators were sparse (Kuh, 1981), they still may play a part in developing and maintaining a quality academic program.

Additional characteristics associated with program quality are exhibited through the personal actions of students, faculty, and administrators. Examples include "achievement, persistence, purpose, worth, beauty, meritoriousness, and character" (Conrad \& Blackburn, 1985b, p. 286). Other ingredients of quality academic programs discussed by Conrad and Blackburn's (1985b) literature review include accountability, efficiency, effectiveness, and excellence. Quality certainly encompasses accountability, meaning a program meets some minimum set of standards and achieves its goals. It also includes efficiency. "A quality program will more likely be efficient than inefficient” (Conrad \& Blackburn, 1985b, p. 287). However, effectiveness and excellence, as well as accountability and efficiency are often used interchangeably as synonyms for quality (Cameron, 1987).

Kuh's (1981) literature review also revealed educational process and outcome variables as indicators of quality. Kuh categorized these indicators into Stufflebeam's (1971) process and product segments of the context-input-process-product model.

Process or involvement indicators of quality were:

1) instructional activities provided by faculty,

2) informal interaction between students and faculty, and

3) degree and kind of effort both students and faculty invest in their respective roles.

Product Indicators (Outcome Indicators) of Quality were:

1) persistence,

2) student achievement (i.e., GRE scores),

3) intellectual and social/emotional development of students, and

4) alumni achievements such as income and community service (Kuh, 1981).

The literature's emphasis on process and product indices of quality supports the position that assessors of quality should not overlook these important areas.

\section{Shifting View of Program Quality}

The overriding theme in the literature concerning academic program quality and effectiveness is that scholars find it hard to agree on which indicators should be used to determine program quality (Cameron, 1987; Tan, 1992). They have listed many input variables 
as noted in reviews of research literature and an increasing number of environment and outcome variables. For example, Astin’s (1985, p.60-61) “talent-development” concept of educational quality is that "true excellence lies in the institution's ability to affect its students and faculty favorably, to enhance their intellectual and scholarly development, and to make a positive difference in their lives." This view of quality, labeled the value-added view, does focus more on process (environment) and outcome indicators of quality.

Conrad and Pratt (1985) also present questions about processes such as what should be the percentage of time devoted to teaching, research, and service in the university, and, what does a commitment to those percentages look like in terms of academic processes? Examples of these academic processes are faculty-student interactions and development of students' critical thinking and problem solving ability. The processes taking place within the design of an academic program can be very important indicators of program quality. Also, the "extra curriculum" needs to be considered in an evaluation of academic program quality since the activities of students outside the classrooms certainly may enhance or detract from the overall learning experience of each student (Conrad \& Pratt, 1985; Kuh, Schuh, Whitt, \& Associates, 1991). The extra curriculum may include events such as professional group meetings that are held on or nearby the campus.

All of these considerations point to a multidimensional approach in defining indicators of quality academic programs. Quality indicators should be examined at the program level as well as the institutional level (Fairweather \& Brown, 1991). According to higher education literature, (Astin, 1991; Pace, 1990) focusing more on processes and outcomes will help gain a better perspective on the overall indicators of quality in academic programs.

This researcher did not find any studies in aviation or education journals identifying factors of aviation program quality or specific methods of measuring aviation program quality other than the accreditation standards. This lack of specific baccalaureate aviation program quality criteria gives rise to many questions. These questions include: 1) What are the indicators aviation program administrators should establish in developing a high quality aviation program, 2) How does one know if a baccalaureate aviation program in this country is of high quality, and 3) What criteria should be used to determine a program's quality? Although initial accreditation standards have been implemented, the accreditation criteria mainly address input variables (e.g., resources, facilities, faculty) of a baccalaureate aviation program. Little assessment of an aviation program's environment or outcome variables are mentioned. However, the current emphasis in the literature is on the environment of academic programs as well as the outcomes of those programs. It seems appropriate to study all aspects of U.S. baccalaureate aviation programs in a quest to find a comprehensive set of criteria that support a definition or theory of quality within baccalaureate aviation programs.

\section{Purpose}

In an effort to promote higher quality U.S. baccalaureate aviation programs, the overall purpose of this study was to identify criteria that, as indicators of program quality, support a ranking of the highest quality programs. This manuscript identifies the indicators of quality among the highest quality U.S. baccalaureate aviation programs.

\section{Methodology}


In the absence of any studies on baccalaureate aviation program quality, an independent measure of quality was administered in this research study. Aviation industry and aviation education experts were asked to identify the highest quality baccalaureate aviation programs in the country for the purpose of finding corresponding criteria to support the identified high quality programs. This procedure allowed experts to focus on specific criteria they identify as characteristic of the highest quality programs. An example of this type of research was accomplished by Mijares (1988) in another professional baccalaureate program--criminal justice. Through grounded theory research using Glaser and Strauss' (1967) constant comparative analysis, criteria used to support a ranking of programs went beyond a reputational ranking of baccalaureate criminal justice programs.

The methodology for this study, based on Glaser and Strauss' (1967) grounded theory constant comparative analysis, was chosen because the literature did not provide a clear definition of quality, especially in regard to professional baccalaureate aviation programs. Since quality is addressed in the literature as multi-dimensional, context specific, and shifting more toward process and outcome variables of the academic environment, a grounded theory approach to studying aviation programs, a relatively new academic program in higher education, seemed the most appropriate.

The unit of analysis in this study was U.S. baccalaureate aviation programs offering flight education as part of an aviation-related baccalaureate degree. There are 276 postsecondary education institutions in the United States offering non-engineering aviation programs (UAA, 1994). Of these institutions, 70 offer baccalaureate degrees in aviation-related areas involving some form of flight education. These 70 baccalaureate programs were identified from the most current Collegiate Aviation Directory (UAA, 1994). The 70 baccalaureate programs are generally located at Carnegie classified comprehensive I and II institutions throughout the country with a few at research universities and private nonsecular colleges. This research focused on these 70 programs since the other 206 institutions are either associate degree programs or certificate offering programs and are quite diverse in nature. There are also six baccalaureate aviation programs that did not offer any flight education in conjunction with aviation management degrees that were not included in this study. In order to keep the study's context specific, as recommended by Conrad and Pratt (1985), these programs were not included in this study since the study focused on only those academic programs providing flight education as an integral part of the baccalaureate degree.

\section{Subjects}

The sample population for this study included all 70 U.S. baccalaureate aviation program administrators and 89 U.S. aviation industry experts. The 89 aviation industry experts included 16 top-level FAA administrators, 18 directors of flight operations/training from U.S. based major/national airlines, and 55 directors of flight operations/training from U.S. based regional airlines. Because the number of regional airlines in each of the nine FAA regions varies widely, regional airline directors of flight operations/training were randomly selected from the nine FAA regions in the United States using probability proportionate to size sampling (Babbie, 1973). Thus, $37.5 \%$ of the regional airlines in each region were queried to obtain a sample size of 55 . Fifty-five regional airlines were selected in an effort to obtain 27 responses (approximately 50\%) from the regional airlines so that the combined industry and government (FAA) response would be approximately the same as the academic administrators' response. 


\section{Instrumentation}

The instrument was an open-ended questionnaire designed to gather data for qualitative analysis. The questionnaire was pilot tested on a random sample of nine directors of operations/training from the U.S. regional airlines. The pilot test results showed that follow-up telephone calls were effective in obtaining a 67\% response rate. The data obtained in the pilot study also showed 1) there was a range of quality existing in U.S. baccalaureate aviation programs, 2) there was some agreement as to which programs are the highest quality programs, and 3) the criteria used to identify these high quality programs showed similarities among respondents. Minor modifications in instrumentation and protocol were made as a result of the pilot study.

Participation was invited through a cover letter to each identified expert, with an explanation of the survey and a discussion of the study's possible benefits. Consent to participate was indicated by returning the questionnaire. A phone number was included for study participants to call if a report of the completed study results was desired.

\section{Data Collection}

The 130 experts were asked to select and rank programs they felt were the ten highest quality baccalaureate aviation programs in the country; they also listed criteria that formed the basis for their rankings. The requirement for listing criteria was used to prompt the experts to base their rankings on more than just reputation. The frequency with which a program was ranked in the top ten was used to quantify the dependent variable in the study, program quality. The criteria given by the experts were analyzed through Glaser and Strauss' constant comparative analysis and identified as indicators of program quality. The researcher carried out the study while affiliated with the University of Michigan. Therefore, respondent bias of identifying the researcher with a particular aviation program would not be an issue.

Participants were asked to complete and return the questionnaire in a prepaid addressed envelope. Follow-up postcards were sent to participants that had not returned the questionnaire. A follow-up letter was sent to all non-respondents twice after the postcards were sent. Finally, telephone calls were initiated eight weeks after the questionnaires were first mailed to all nonrespondents. If the respondent requested to answer questions over the telephone, the same protocol was followed and questions were asked exactly as they appeared on the questionnaire. Table 1 summarizes the phase one data collection response rates.

Because all but one FAA expert felt they were either not in a position to judge the quality of U.S. baccalaureate aviation programs or it would be a conflict of interest if they did judge the programs, the 16 FAA experts were dropped from the sample population of experts. Colleges or universities that had discontinued their baccalaureate aviation program were also dropped from the sample. Similarly, regional airlines that had ceased operations were not included. 
Table 1. Phase One Response Rates

\begin{tabular}{|l|c|c|}
\hline \multicolumn{2}{|c|}{ Response Rates } \\
\hline \multicolumn{1}{|c|}{ Group } & Sample & $\%$ \\
\hline Academic Administrators & 48 of 68 & $71 \%$ \\
Major/national airline directors of flight \\
operations/training & 10 of 18 & $56 \%$ \\
Regional airline directors of flight & & \\
operation/training & 24 of 44 & $55 \%$ \\
& & \\
Overall Response Rate & & \\
\hline
\end{tabular}

\section{Results and Discussion}

The criteria obtained from the questionnaire were used to develop a grounded theory of quality in baccalaureate aviation programs using Glaser and Strauss' (1967) constant comparative analysis. Glaser and Strauss' methodology identifies the dependent variable as the constant (program quality) and the independent variables as the comparative data (quality criteria). The dependent variable in this study was measured by the frequency of top ten rankings of the baccalaureate aviation programs, while the criteria given by the experts to support the top ten rankings were the independent variables and identified as indicators of quality.

Data obtained from the three groups of experts (aviation program administrators, major/national airline directors of operations/training, and regional airline directors of operations/training) were analyzed separately to determine degree of group variability. The criteria were compiled by ranking for each expert group. For example, all the criteria listed for each number one program ranked by the academic administrators were grouped together followed by all criteria for the number one program ranked by the major/national directors of flight operations/training.

The criteria from the three groups of experts were used to develop a model of program 
quality in U.S. baccalaureate aviation programs. Ten categories evolved from the criteria listed by the experts to form a model of quality in U.S. baccalaureate aviation programs. Some subcategories were identified to more clearly define particular categories. The ten categories, all indicators of program quality in U.S. baccalaureate aviation programs, and the subcategories are defined as follows:

\section{Curriculum}

a. Curriculum - the breadth and depth of course offerings within the aviation program as well as within the college/university where the program is located.

b. Scholarship - the degree that high academic standards are upheld--the academic rigor and academic credibility of the aviation program.

2. $\quad$ Students

a. Performance of graduates - the desired abilities displayed by the aviation program graduates while on the job, primarily at the regional airlines.

b. Number of students - the number of aviation students within the program as well as the number of students attending the college/university campus. Experts indicated small, medium, and large aviation programs and small, medium, and large college/university campuses as indicators of quality. No clear trend developed.

b. Student selectivity - establishing minimum grade point averages or ACT scores for entrance into the aviation program.

\section{2. $\quad$ Faculty}

a. Faculty - the qualifications and technical expertise of the aviation program's faculty and flight instructors.

b. Instruction - the quality and level of flight instruction given in simulators, aircraft, and the classroom.

c. Dedication - sincere, ceaseless efforts by personnel within the aviation program to offer the best education possible.

b. Research - the degree that aviation program faculty and administration carry out investigations to create new knowledge in the field.

\section{2. $\quad$ Program Activities}

a. Student development/internships - the number and variety of student development opportunities including co-op programs, internships with airlines, industry seminars, professional meetings, etc.

b. Flying team - the perceived success of the aviation program's flying team to the degree it contributes to the overall quality of the program.

c. Industry relations - the ability of the aviation program to actively seek out and establish internship and co-op programs as well as establish on-going working relationships with industry representatives for the improvement of aviation education within that particular program. 
d. Student placement - the degree to which the aviation program aggressively attempts to find employment for its graduates within the aviation field.

e. Student placement - the degree to which the aviation program aggressively attempts to find employment for its graduates within the aviation field.

f. Alumni relations - the degree the aviation program actively receives input from its alumni to enhance its program.

g. Service - the degree the aviation program provides help and expertise to the general public in aviation related areas.

h. Graduate school - the perception that a graduate program in aviation enhances the undergraduate education of a particular aviation program.

i. $\quad$ Advertising - the perception more advertising provides for a higher quality aviation program.

j. Minority recruitment - efforts to recruit and obtain more minority students enhances the aviation program's educational experience.

2. Equipment - the number and variety of simulators and aircraft the aviation program has for use by its students. Computer equipment is also included.

3. $\quad \underline{\text { Facilities }}$

a. Facilities - the physical plant of the aviation program, i.e., buildings, classrooms, airport hangars, briefing rooms, etc.

b. Location - the geographic location of the program provides for a better education for the student.

2. Leadership

a. Leadership - the demonstrated ability of the aviation program's administration and faculty to lead their program toward excellence.

b. Innovation - the ability of aviation program administration, faculty, and staff to continually think of improved ways of educating our future aviation professionals.

\section{Resources}

a. Resources - the internal and external funding sources available to the aviation program.

b. Grantsmanship - the ability of the aviation program to successfully compete for outside agency funding.

9. Reputation - the general knowledge by the expert that the aviation program is well respected in aviation education/aviation industry circles.

10. Value (cost) - the perception that the aviation program's offerings are worth the cost of 
tuition and flight program fees.

Table 2 identifies the percentage of experts from each of the three expert groups that mentioned each of the ten criteria categories. The academic administrators view quality aviation programs from more of a multi-dimensional perspective than experts from the aviation industry, especially experts from the regional airlines. The regional airline experts focused almost entirely on the student category, specifically the performance of graduates. When combining all three groups, the order of importance for each criteria category that emerged was 1) curriculum, 2) students, 3) faculty, 4) program activities, 5) equipment, 6) facilities, 7) leadership, 8) resources, 9) reputation, and 10) value.

\section{TABLE 2. Percentage of Each Expert Group Mentioning Each Indicator of Quality Category}

\begin{tabular}{|l|c|c|c|c|}
\hline & $\begin{array}{c}\text { Academic } \\
\text { Administrators }\end{array}$ & $\begin{array}{c}\text { Major } \\
\text { Airlines }\end{array}$ & $\begin{array}{c}\text { Regional } \\
\text { Airlines }\end{array}$ & $\begin{array}{c}\text { All Groups } \\
\text { Combined } \\
\end{array}$ \\
$\begin{array}{l}\mathrm{N}=68 \\
\%^{\mathrm{a}}\end{array}$ & $\begin{array}{c}\mathrm{N}=18 \\
\%^{\mathrm{a}}\end{array}$ & $\begin{array}{c}\mathrm{N}=130 \\
\%^{\mathrm{a}}\end{array}$ \\
\hline Curriculum & 88 & 43 & 18 & 67 \\
Students & 50 & 71 & 100 & 63 \\
Faculty & 74 & 57 & 9 & 58 \\
Program Activities & 62 & 29 & 9 & 46 \\
Equipment & 53 & 14 & 9 & 38 \\
Facilities & 47 & 14 & 9 & 35 \\
Leadership & 18 & 29 & 9 & 17 \\
Resources & 26 & 0 & 0 & 17 \\
Reputation & 24 & 14 & 0 & 6 \\
Value & 6 & 14 & 0 & 17 \\
\hline
\end{tabular}

a Percentages figured by dividing total number of experts mentioning criteria for the top ten programs by the number of experts mentioning criteria for each category.

\section{Developing a Model of Aviation Program Quality}

The quality criteria listed by the experts formed the ten categories for the development of a model that depicts the make-up of program quality in U.S. baccalaureate aviation programs. Figure 1 displays the model with the ten criteria categories. The diameter of the circle for each 
category of the model represents the approximate percentage of experts mentioning criteria within each indicator of quality category.

The ten indicators of quality within the model resemble other academic program quality studies to some extent. For example, Mijares' (1988) study of criminal justice programs found similar indicators, or factors, leading to a reputation of program excellence. The similar factors were curriculum, faculty, resources and facilities, and students. Also, Mijares' study identified size as a separate factor, whereas in this study, it was associated with students, similar to Conrad and Blackburn's (1985) study. However, other factors identified in the Mijares study, dissimilar to this study, were public service, association activity, graduate school, and age. Reasons for these differences may be numerous, but could include the fact that criminal justice programs emerged prior to a majority of aviation programs. Additionally, when considering these dissimilar factors, it is interesting to note that even in two relatively new professional academic programs such as criminal justice and aviation, academic program quality is defined differently. This does support Conrad and Pratt's (1985) research suggesting program quality be defined within a specific context. The results also support one of Fairweather and Brown's (1991) perspectives on academic program quality, that academic program quality is dependent upon departmental or program variables and not institutional variables. For example, most of the indicators of quality defined in the model of program quality in U.S. baccalaureate aviation programs pertain to specific departmental characteristics and not institutional characteristics.

\section{Multi-dimensional Nature of Four-year Aviation Program Quality}

The criteria for program quality data obtained were certainly multi-dimensional in nature, given the frequency different criteria were listed by the aviation education and aviation industry experts. Granted, the criteria listed by aviation industry experts were not as extensive as criteria listed by the academic administrators. However, the emphasis the industry placed on the performance of aviation program graduates is understandable, since it is a critical element in the airline industry's day-to-day operation. Having well-educated aviation professionals readily able to meet the high pressure demands of the airline industry is essential for the continued success of the company. Thus, the perception by the airline industry that the performance of graduates is the overriding and predominant indicator of quality appears to be well founded.

It is interesting to note that the criteria used by the experts paid little attention to the reputation of the baccalaureate aviation programs, a variable often criticized in the past for having too much emphasis in academic program quality studies. The differences between academic administrators and industry, though, do suggest that academic administrators should possibly be focusing more attention on what happens to their graduates within the aviation industry in order to monitor where changes in their particular aviation program need to be made.

Some bias in the quality criteria data may be present, since the regional airline directors of operations/training were not as familiar with as many of the baccalaureate aviation programs as the academic administrators. When it came to ranking programs, the regional airline directors could only rank programs that they knew about, and those programs tended to be programs located nearby. However, the bias was counteracted by the fact that among the FAA regions of the country from which the regional airline experts were selected, the response rates from each region were similar. Thus, the regional bias factor should have canceled itself out with similar 
response rates from all regions.

A discussion of which criteria or indicators of quality identified are most important is warranted. Through an examination of Figure 1, it is appropriate to state that the experts listed the curriculum category most frequently as a criterion for quality. Using these qualitative data, curriculum would be listed as the most important indicator of quality followed by students, faculty, program activities, equipment, facilities, leadership, resources, reputation, and value. These criteria categories, or indicators of quality, all play a part in how the aviation education and aviation industry experts view quality.

\section{Implications of the Study}

The implications of this research study verify that program quality is multi-dimensional in nature, similar to Conrad and Blackburn's (1985) study of graduate programs and congruent with one of Fairweather and Brown's (1991) perspectives on quality. Identifying the indicators of U.S. baccalaureate aviation program quality in this study supports the premise that the indicators contain input, environment, and outcome variables. Industry mainly focused on student outcomes as an indicator of quality while the academic administrators focused on environment and input variables such as curriculum, faculty, students and program activities. Although the experts did not provide supportive data that aviation program quality is primarily defined through environment and outcome variables, it is evident from the criteria obtained that a shift toward these areas has occurred in baccalaureate aviation programs. This shift also may be occurring in other professional education programs. Researching other professional academic programs to validate the results of this study, including two year aviation programs, would be beneficial.

The information produced as a result of the study should not be considered conclusive in nature. Since this is the first attempt at identifying indicators of quality in U.S. baccalaureate aviation programs, further research is needed to compliment the study. Additionally, a more comprehensive review of a greater number of U.S. baccalaureate aviation programs would also prove helpful in providing supportive data as to which indicators of quality should garner the most attention when providing the highest quality baccalaureate aviation education.

\section{References}

Astin, A. W. (1985). Achieving educational excellence. San Francisco: Jossey-Bass.

Astin, A. W. (1991). Assessment for excellence: The philosophy and practice of assessment and evaluation in higher education. New York: MacMillan.

Cameron, K. S. (1987). Improving academic quality and effectiveness, in M. W. Peterson and L. A. Mets (Eds.) Key resources on higher education governance, management, and leadership, pp. 322-346. San Francisco: Jossey-Bass.

Conrad, C. F., \& Blackburn, R. T. (1985b). Program quality in higher education: A review and critique of literature and research. In Higher education: Handbook of theory and research, Vol. I, pp. 283-308. New York: Agathon Press.

Conrad, C. F., \& Pratt, A. M. (1985). Designing for quality. Journal of Higher Education, $\underline{56}$ (6) 601-621. 
Conrad, C. F., \& Wilson, R. F. (1985). Academic program reviews: Institutional approaches, expectations, and controversies. ASHE-ERIC Higher Education Reports. No. 5. Washington, DC: The George Washington University.

Fairweather, J. S., \& Brown, D. F. (1991). Dimensions of academic program quality. The Review of Higher Education, 14 (2) 155-176.

Federal Aviation Administration. (1993). Pilots and aviation maintenance technicians for the twenty-first century: An assessment of availability and quality. Washington, D.C.: U.S. Department of Transportation.

Glaser, B. G., \& Strauss, A. L. (1967). The discovery of grounded theory: Strategies for qualitative research. Chicago: Aldine Publishing Company.

Kuh, G. D. (1981). Indices of quality in the undergraduate experience. AAHE-ERIC Higher Education Research Report No. 4. Washington, D.C.: American Association for Higher Education.

Kuh, G. D., Schuh, J. H., Whitt, E. J. \& Associates. (1991). Involving colleges. San Francisco: Jossey-Bass.

Mijares, T. C. (1988). Program quality and the emergence of criminal justice education. Dissertation. Ann Arbor, MI: The University of Michigan.

Millard, R. M. (1991). Today's myths and tomorrow's realities. San Francisco: Jossey-Bass.

Pace, C. (1990). The undergraduates: A report of their activities and progress in college in the 1980s. Los Angeles: University of California, Center for the Study of Evaluation.

Stufflebeam, D. L., et al. (1971). Educational evaluation and decisionmaking. Itasca, IL: Peabody.

Tan, D. L. (1992). A multivariate approach to the assessment of quality. Research in Higher Education, 33 (2) 205-226.

University Aviation Association (UAA). (1994). Collegiate Aviation Guide. Auburn, AL: University Aviation Association.

University Aviation Association (UAA). (1989). Collegiate aviation directory. Atlanta, GA: Future Aviation Professionals of America.

Wells, A. T. (1993). Air transportation: A management perspective. Belmont, CA: Wadsworth. 